\title{
Putnam, Ética e Biologia
}

\author{
Charles Feldhaus
}

\begin{abstract}
This study reconstructs the main criticisms of Hilary Putnam against those who try to belittle the moral philosophy based on ontological and epistemological considerations, arguing among other things that moral judgments lack scientific status, because they lack objects and consequently of truth conditions and so they would be reduced to merely emotive statements. Furthermore, this study reconstructs the general traits of Allan Gibbard's norms expressivism in light of the criticisms of Putnam. Finally, we reconstructed some of the main criticisms of Jürgen Habermas to Gibbard's norm expressivism.
\end{abstract}

Keywords: Ethics; ontology; evolutionary biology; pragmatism; norms expressivism.

Yet most analytic philosophy of language and much analytic metaphysics and epistemology has been openly hostile to talk of human flourishing, regarding such talk as hopelessly "subjective" - often relegating all of ethics, in fact, to that wastebasket category.

(H. Putnam, The Collapse of the Fact-Value Distinction, p.viii)

\section{Introdução}

Mesmo que as principais preocupações de Hilary Putnam não tenham sido no campo da filosofia moral ou ética, sem dúvida ele contribuiu de maneira significativa para esse campo da reflexão filosófica. Em sua obras Ethics Without Ontology e The Collapse of the Fact/Value Dichotomy, Putman argumenta contra uma concepção moral metafisicamente inflacionada e a favor de um pluralismo pragmático. Defende ainda que grande parte dos problemas filosóficos no campo da reflexão moral tem sua origem na dicotomia entre fatos e valores. Além disso, Putman pretende reinterpretar a concepção de objetividade na ética, isto é, tenta salvar a objetividade nos julgamentos morais, sem com isso se comprometer com o realismo moral. Ele pretende, assim, encontrar um modo não metafísico de pensar a objetividade da moralidade, apesar de reconhecer que a mesma carece de objetos externos à mente aos quais os enunciados morais possam se conformar. Com o avanço dos estudos no campo da biologia evolutiva, alguns pensadores têm tentando explicar a moralidade à luz da teoria da evolução. Com isso, eles pretensamente explicariam as regras morais e seu caráter obrigatório sem precisar recorrer a entidades metafísicas. Do ponto de vista de Putman, esta poderia ser uma vantagem explicativa, uma vez que consistiria numa abordagem moral mais econômica no que diz respeito à ontologia pressuposta. Mas, de fato, Putnam concordaria com essa abordagem à reflexão moral? Ou talvez,

Principia 17(3): 489-503 (2013).

Published by NEL — Epistemology and Logic Research Group, Federal University of Santa Catarina (UFSC), Brazil. 
esse tipo de abordagem estaria comprometida com as mesmas pressuposições equivocadas que Putnam recusa-se a aceitar? Retornaremos a essa questão ao final do presente estudo.

Não obstante, tentativas de explicar a moralidade à luz da biologia também tem sido frequentemente criticadas. Uma das mais famosas objeções, normalmente lembrada quando se pretende criticar as explicações biológicas da moralidade, é a que George Moore desenvolve em sua obra Principia Ethica. Moore sustenta que várias teorias éticas, o que não se restringe obviamente as teorias éticas baseadas na biologia evolutiva, têm cometido o que ele denomina de falácia naturalista, ou seja, a identificação ou a inferência de valores morais a partir de fatos naturais ou metafísicos. Porém, algumas teorias éticas baseadas na biologia têm conseguido oferecer uma abordagem da ética, sem contudo cometer a falácia naturalista, como o faz, por exemplo, o expressivismo de normas de Allan Gibbard. ${ }^{1}$ Gibbard não apenas não comete a falácia naturalista, uma vez que nem mesmo identifica termos avaliativos com propriedades físicas ou naturais, como não realiza qualquer inferência baseada nesse tipo de identificação. Entretanto, apesar da aparência inicial de ser uma abordagem que possui significativas vantagens explicativas em relação às teorias morais concorrentes, uma vez que explicaria os fenômenos morais com uma ontologia mais modesta, alguns pensadores, entre os quais Habermas, ${ }^{2}$ procuram mostrar que esse tipo de abordagem é insuficiente como uma estratégia explicativa da moralidade, uma vez que é incapaz de dar conta da fenomenologia moral ordinária. Retornaremos às críticas de Habermas à abordagem de Gibbard mais adiante.

\section{Putnam, ontologia e moralidade}

Em seu livro Ethics Without Ontology, Putnam afirma que

ética e matemática podem ter e de fato têm objetividade sem que esteja se referindo a objetos sublimes ou intangíveis, tal como as 'formas platônicas' ou 'entidades abstratas,' e que a ideia que 'existe' tem significado único e determinado, que se pode marcar no mármore, por assim dizer, é errônea. (Putnam 2004, p.2, nossa tradução)

Putnam pretende "encontrar um caminho que mantenha a verdade no falibilismo, sem abandonar o jogo ao ceticismo" (2004 p.16). Putnam começa definindo os extremos dentro do âmbito das posições ontológicas possíveis no campo da ética, os quais ele pretende evitar: a) ontologia inflacionada; e b) ontologia deflacionada. Além disso, ele procura deixar claro, desde o princípio, o que entende pelo termo 'ética', a fim de não ser mal compreendido a respeito do que pretende defender exatamente.

Segundo Putnam, advogam algum tipo de ontologia inflacionada aqueles filósofos que estão comprometidos com "a existência de coisas deconhecidas à percepção 
sensorial ordinária e ao senso comum, na realidade coisas que são invisíveis [...]. Além do mais, essas coisas invisíveis que o ontologista inflacionário afirma ter descoberto são consideradas muito importantes." (2004, p.17) Ele considera que Moore seria o exemplo de um filósofo que estaria comprometido com uma ontologia inflacionada, apesar das críticas de Moore à identificação de enunciados morais com propriedades metafísicas ou naturais. Moore denominou esse tipo de equívoco de falácia naturalista (1903, p.13). Essa crítica é muito lembrada como uma forte objeção àqueles que tentam explicar a moralidade à luz da biologia. Entretanto, para Putnam, Moore afirma que propriedades morais não são nem físicas nem metafísicas, mas propriedades sui generis (para usar um termo de Dall'Agnol), a saber, um tipo de qualidade suprasensível e que exigiria uma capacidade cognitiva especial para sua apreensão, uma vez que essa faculdade seria completamente distinta da sensibilidade e do entendimento. Essa faculdade Moore chamou de intuição. Desse modo, Moore estaria comprometido com um tipo de realismo moral forte, uma vez que parece admitir que essas propriedades morais existem independente da mente dos seres humanos que as apreendem. Neste artigo, contudo, não pretendo examinar a fundo o mérito da identificação do intuicionismo moral de Moore com algum tipo de realismo moral, e consequentemente uma metafísica inflacionada.

Putnam atribui uma metafísica deflacionada àqueles filósofos que se vinculam a algum tipo de reducionismo ou de eliminacionismo. O reducionismo afirma que termos morais são por exemplo "nada senão o prazer [...] que juizos éticos não são senão expressões de sentimentos" (2004, p.19). Para Putnam, o nominalismo, na história da filosofia, teria sido um tipo de ontologia deflacionada, uma vez que, na querela a respeito dos universais, afirmava que não há nada além dos nomes. No âmbito da ética, um eliminacionista defende que não há algo a que termos morais como bom refiram-se, ou que empregar esses termos num sentido realista seria um erro. Este é o caso de Mackie, por exemplo, que em Ethics - Inventing Right and Wrong, defende que a linguagem moral ordinária age como se enunciados morais tivessem realidade e caráter obrigatório quando na verdade essa visão seria um autoengano coletivo do seres humanos enquanto espécie, porque juízos morais consistem apenas em expressões de sentimentos morais dos falantes e que os juízos morais carecem de toda objetividade e obrigatoriedade que parecem possuir na linguagem moral ordinária (Mackie 1977, p.35). Nos termos de Putnam, Mackie defende que "nossa fala ordinária é, do ponto de vista cognitivo exatamente tão equivocada como a fala da alquimia, ou do flogisto ou dos feiticeiros" (Putnam 2004, p.21).

Por ética, ele entende "não um sistema de princípios [...] embora princípios sejam certamente um parte da ética — mas antes um sistema de preocupações interrelacionadas, preocupações que vejo como se apoiando mutuamente mas também em parcial tensão" (2004, p.22). Além disso, Putman vincula sua posição ética ao pragmatismo e afirma que, da mesma forma que Dewey, ele acredita que a ética 
está preocupada com a solução de problemas práticos, a saber, “"problemas que encontramos na prática', específicos e situados, em oposição a problemas abstratos, idealizados e teóricos" (2004, p.28). A visão normativa de Putnam se situa dentro do espectro do pluralismo moral, que ele procura diferenciar do relativismo moral (Bernstein, p.259).

\title{
2. A Ética a a objetividade dos julgamentos morais em Putnam
}

O principal objetivo de Putnam ao tratar da filosofia moral ou ética, não é desenvolver uma teoria moral substantiva com um código de deveres e obrigações específicas, mas atacar algumas abordagens contemporâneas que procuram desmerecer a reflexão moral baseadas em considerações epistêmicas e ontológicas a respeito dos enunciados morais contrastando-os com os enunciados das ciências. Entre tais abordagens pode-se ressaltar o positivismo lógico de Carnap, o emotivismo moral de Mackie e o intuicionismo moral de Moore. Como já afirmamos, Putam critica Moore por seu pretenso comprometimento com uma ontologia inflacionada. A crítica ao positivismo e ao emotivismo moral, por sua vez, é indireta, na medida em que ele tenta mostrar que essas posições assumem pressuposições equivocadas. Entre essas pressuposições equivocadas está a visão de que se pode traçar uma separação nítida entre enunciados fáticos e enunciados normativos, entre enunciados que são dotados de objetividade e enunciados que são carentes de objetividade.

Sobre esse ponto convém citar uma passagem elucidativa de Putnam (2002, p.1):

\begin{abstract}
A ideia que 'juízos de valor são subjetivos' é uma peça de filosofia que gradualmente chegou a ser aceita por muitas pessoas como se fosse senso comum. Nas mãos de pensadores sofisticados essa ideia pode ser e tem sido desenvolvida de diferentes modos. Aqueles com os quais me ocuparei sustentam que 'afirmações de fato' são capazes de ser 'objetivamente verdadeiras' e capazes, também, de ser 'objetivamente justificadas', enquanto juízos de valor, segundo esses pensadores, não são passíveis de verdade e garantia objetivas. Juízos de valor, segundo os mais extremos proponentes de uma forte dicotomia 'fato e valor' estão completamente fora da esfera da razão.
\end{abstract}

Essa passagem marca significativamente o itinerário que Putnam pretende seguir ao tratar do tema da objetividade dos juízos morais, o que ele chamará de objetividade sem objetos. Sua estratégia argumentativa consiste, assim em mostrar que, mesmo que juízos e termos morais não se refiram a objetos (ou a propriedades, mesmo que sui generis), como Moore parece ter sustentado, eles ainda possuem algum tipo de objetividade. Para mostrar isso, Putnam reconstitui brevemente a história da origem da dicotomia entre fatos e valores. Putnam defende que a dicotomia entre fatos e valores é de alguma forma dependente da dicotomia entre dois tipos de enunciados,

Principia 17(3): 489-503 (2013). 
isto é, entre juízos analíticos e juízos sintéticos. Para Putnam (2002, p.17), a distinção entre fatos e valores remonta à distinção de Hume entre questões de fato e relações de ideias, tal como ele a apresenta em sua obra An Enquiry concerning $\mathrm{Hu}$ man Understanding (1999, p.108), e à apropriação que os positivistas lógicos fizeram dessa distinção. Segundo Putnam:

os positivistas lógicos recorrem a uma versão amplamente inflacionada da ideia de Hume que juízos éticos não são afirmações de fato, mas antes são ou expressões de sentimentos ou imperativos disfarçados. (2002, p.17, nossa tradução)

Putnam considera, assim que os positivistas lógicos adotaram uma leitura da distinção entre juízos analíticos (relações de ideias) e juízos sintéticos (questões de fato) forte atribuindo aos juízos éticos um estatuto similar ao juízos estéticos, ou seja, sem possibilidade de discussão racional alguma porque os mesmos não são senão a expressão dos estados volitivos do falante, o que pode implicar, por exemplo, que dois falantes possam proferir dois enunciados morais contrários a respeito do mesmo caso, nas mesmas circunstâncias e com isso não incorrer em nenhum tipo de contradição. A ideia básica aqui é que os positivistas lógicos, supostamente baseados em Hume, teriam traçado uma classificação entre três tipos de juízos: 1) juízos sintéticos ou de experiência; 2) juízos analíticos, os enunciados da matemática, por exemplo; e, finalmente, 3) juízos carentes de sentido ou contra-sensos. Como os enunciados éticos não teriam objetos correspondentes, não poderiam ser considerados como juízos de objetos de experiência ou sintéticos. Uma vez que estariam sujeitos a controvérsia moral, não se pode sustentar, apenas com base na análise de seus conceitos, que seriam verdadeiros e, por isso, não podem ser considerados como analíticos, como alguns acreditavam que sucederia com os enunciados matemáticos, por exemplo. Por conseguinte, raciocinando por eliminação, os enunciados morais seriam considerados juízos carentes de sentido ou contra-sensos e relegados ao estatuto de enunciados de segunda categoria.

Quanto à leitura do positivismo da ideia original de Hume convém ressaltar apenas que, para Putman (2002, p.18), Hume carece de um termo específico para aquilo que denominamos atualmente de juízos morais e também que ele não defende uma posição pejorativa da ética, no sentido de que a ética não pudesse ser incluída no campo dos fatos (ou das questões de fatos, para usar a terminologia de Hume). Hume não queria dar a entender que "a possibilidade de um filósofo escrever um manual de ética" estivesse descartada, uma vez que livros de éticas conteriam apenas contra-sensos, mas os positivistas lógicos claramente afirmam isso baseados em Hume. Uma forte evidência a favor da interpretação de Putnam da posição de Hume é que este publicou obras de filosofia moral que tratam de assuntos especificamente morais. 
Para permitir a discussão racional no campo da ética, Putnam (2002, p.21) se dedica a mostrar como a revisão empreendida pelo positivismo lógico de fato "destrói a própria base na qual eles ergueram a dicotomia entre fatos e valores". Para Hume (Putnam 2002, p.21), fatos se refeririam às impressões dos sentidos. Contudo, com o passar do tempo novas teorias científicas foram desenvolvidas no campo da biologia, da física, da química, as quais empregavam termos cujos referentes não podiam ser observáveis como fatos no sentido simples de uma impressão dos sentidos, tal como compreendia Hume. Com o passar do tempo, a filosofia da ciência se sofisticou e começou a sustentar que, a fim de que um enunciado científico fosse considerado significativo cognitivamente ele precisaria poder ser expresso na linguagem da ciência e os termos do predicado deveriam poder ser expressos em termos de observação ou redutíveis a esses termos (Putnam 2002, p.23). Após isso ainda, diz Putnam (2002, p.24), positivistas como Carnap diferenciaram entre termos observáveis, que são completamente interpretados, e termos observáveis, que são apenas parcialmente interpretados. Enfim, a distinção originária entre ideias e impressões, por parte de Hume, originou a crítica dos positivistas ao caráter científico dos enunciados morais e terminou por colocar os próprios enunciados científicos em uma situação desconfortável, razão pela qual a noção teve que ser reformulada.

Outros pontos que Putnam ataca, a fim de minar a dicotonomia entre fatos e valores, é a suposta neutralidade axiológica da ciência e a própria pobreza da linguagem do positivismo lógico, que seria incapaz de captar minúcias linguísticas. Ele apresenta o exemplo do emprego do termo 'cruel' por um historiador do período romano, usando esse termo para falar de um dos imperadores. Então pergunta: esse termo está sendo empregado como um termo observacional ou como um termo teórico? Como cruel não parece um termo observacional simples teria que ser um termo teórico, mas então surge a questão: quais seriam os postulados que geralmente acompanham os termos teóricos, nesse caso do emprego de 'cruel' em livros de história? Para Putnam (2002, p.27), os positivistas lógicos "falharam em apreciar os modos em que descrições factuais e valorações podem e devem estar envolvidos [entagled]." Ou seja, não é correta a afirmação que fatos e valores são completamente separados e distintos, mas que a ciência pressupõe valores e a ética também possui uma parte descritiva. E é a incapacidade de muitos teóricos da ética contemporânea de perceber que valores e fatos diferem apenas em grau e não em tipo, que, segundo Putnam, teria causado grande confusão no campo da reflexão moral contemporânea, entre os quais estaria a alocação da ética no âmbito do contra-senso. Com o que concorda Bernstein (p.253), ao comentar essa posição de Putnam:

concordo completamente com ele [Putnam], a dicotomia valor e fato tem tido influência pervasiva e perniciosa nas ciências sociais, assim como na nossa compreensão ordinária dos julgamentos éticos e políticos. Poucos filósofos que endossam a dicotomia fato e valor subscrevem ao emotivimo -

Principia 17(3): 489-503 (2013). 
a tese que a função primária dos juízos de valor é expressar ou revelar emoções. Mas muitos afirmariam que juízos de valor são não-cognitivos; eles não são o tipo de juízos que podem ser verdadeiros ou falsos. Na melhor das hipóteses, tais juízos nada são a não ser a expressão de preferências ou de atitudes individuais (ou de grupos). (Bernstein, p.253, nossa tradução)

Desse modo, para Putnam (2002, p.30-1) “juízos normativos são essenciais à própria prática da ciência" e ele cita como exemplos de valores que estão implicados na prática científica os seguintes: juízos de coerência, pausibilidade, razoabilidade e simplicidade. Para Bernstein (p.254), “o ponto de Putnam é que não existe nenhum modo de dar sentido a esses conceitos a não ser que compreendamos que eles são valores e envolvem juizos normativos sobre o que dever ser; eles não podem ser analizados ou reduzidos ao que é meramente factual." Embora alguém possa afirmar que, mesmo que se aceite que a prática da pesquisa científica opte entre teorias rivais orientada por esse tipo de valores, é preciso reconhecer que tais valores são epistêmicos e não valores morais. Não obstante, é preciso ressaltar que o próprio Putnam está, de certa forma, ciente disso, embora busque mostrar que, mesmo que se aceite essa diferença, essa diferença não justifica a assimetria normalmente criada entre o estatuto dos enunciados científicos e o dos enunciados morais. Alguns diriam que a diferença entre os valores orienta-se pela busca da objetividade nas ciências e a total carência de objetividade na ética, mas este é exatamente o ponto que Putnam pretende atacar (2002, p.32). Segundo Putnam entender esse ponto exige que se considere com clareza o que "se pretende dizer e o que não se pretende dizer [quando se afirma] que valores epistêmicos orientam-nos na busca das corretas descrições do mundo". No fundo, a pergunta é: ao nos orientarmos por esses valores epistêmicos, estaremos de fato fazendo uma descrição correta do mundo? Além do mais, é adequado sustentar que apenas os juízos, que constituem uma correta descrição do mundo, podem ser considerados objetivos? Putnam (2002, p.33) defenderá que não apenas na ética, mas também em outros campos como a lógica e a matemática é possível falar de objetividade sem objetos. E se é assim, como se pode explicar a assimetria entre o estatuto epistêmico atribuído a esses enunciados e os enunciados científicos, sem supor algum tipo de arbitrariedade? Ou seja, Putnam considera injustificada e arbitrária a atitude de muitos filósofos contemporâneos em relação à ética, se não for possível explicar em que enunciados morais e enunciados científicos se diferenciam, uma vez que se torna obscura a diferença baseada na ausência ou presença de valores, dado que enunciados morais e científicos implicam valores, e uma vez que existem enunciados científicos dotados de objetividade mas carentes de objetos.

Principia 17(3): 489-503 (2013). 


\section{Gibbard, Ética e Biologia}

Como já afirmamos, alguns pensadores contemporâneos, preocupados em desenvolver um pensamento ético metafisicamente não inflacionado, têm tentado explicar a moralidade à luz da biologia evolutiva, sem contudo cometer a falácia naturalista. Allan Gibbard, em sua obra Wise Choices, Apt Feelings procura explicar a moralidade com base na biologia.

tentarei esboçar um quadro naturalista da vida normativa humana, e suficiente em que seja coerente e se ajuste aos fenômenos para fazer-me pensar que a verdade pode encontrar-se em alguma parte de sua proximidade. Se for assim, os antigos problemas filosóficos agora surgirão em uma nova forma. Que lugar a racionalidade e a moralidade tem nesse quadro naturalista? Que lugar nossos pensamentos a respeito dessas questões possuem? Um novo tema tem emergido no livro: como podemos nos pensar como membros de uma espécie que se auto-compreende como tendo evoluído biologicamente. (Gibbard 2002, p.viii, nossa tradução)

Entretanto, diferentemente de Putnam, Gibbard defende um tipo de não cognitivismo moral, uma vez que defende que enunciados morais consistam em expressões de aceitação de normas relativas a quando sentir culpa e ressentimento. Nas palavras de Gibbard: "A análise é não cognitivista no sentido estrito que, segundo ela, chamar algo racional não é afirmar uma questão de fato, quer como verdadeira, quer como falsa." (Gibbard 2002, p.8) Além disso, a abordagem de Gibbard evita tratar questões éticas substantivas (Gibbard 2002, p.9), o que não deixa de ser um problema para essa visão. Como veremos mais adiante, Habermas crítica a abordagem expressivista de normas de Gibbard, uma vez que a mesma assume um ônus, que parece incapaz de carregar. Em outras palavras, o expressivismo de normas tem que mostrar como é possível conciliar a explicação biológica da ética com os valores obtidos, no que Gibbard chama de discussão racional (Habermas 1999, p.31-2).

Se agora combinamos essas análises com nossa análise geral [rough analysis] de 'racional', podemos derivar uma análise da distinção entre normas morais e normas de racionalidade. Todas as normas, em certo sentido, são normas para racionalidade, mas normas morais em particular são normas para a racionalidade da culpa e do ressentimento. Considere o que significa uma ação ser 'digna de culpa'. A análise dada até aqui nos diz isso: primeiro, um observador considera um ato como digno de culpa, ou moralmente repreensivel, se e apenas se ele considera que é racional ao agente sentir culpa a respeito do ato, e aos outros ressentir-se com o agente por causa disso. Em segundo lugar, considerar algo como 'racional' é aceitar normas que prescrevem isso. Portanto, podemos concluir que, pensar um ato moralmente repreensível é aceitar as normas que prescrevem, para um tal situação, culpa da parte do agente e ressentimento da parte dos outros. (Gibbard 2002, p.47, nossa tradução)

Principia 17(3): 489-503 (2013). 


\section{Gibbard leitor de Putnam}

É importante enfatizar que Gibbard faz referência à posição de Putnam em sua obra Wise Choices, Apt Feelings, onde ele afirma:

O que, então, [se poderia dizer] da afirmação de Putnam que normas infundem-se em fatos? Com isso eu concordo plenamente: as crenças que estou chamando de factuais dependem de normas epistêmicas, ou normas a respeito de crenças. Que continuemos a sustentar as crenças, que sustentamos, depende de que consideremos que fazer isso faça sentido. Seria incoerente, então, dispensar todos os juízos normativos como meramente subjetivos e ao mesmo tempo aceitar que algumas crenças factuais são firme e objetivamente fundadas. Do ponto de vista da justificação elas estão em posição equivalente; crenças factuais e juízos normativos sustentam-se ou perecem juntos. (Gibbard 1990, p.34, nossa tradução)

Gibbard apresenta, inclusive, um critério pelo qual poderíamos distinguir uma noção que é normativa de uma que não é, ou seja: "se pudermos fazer uma paráfrase dela em termos do que faça sentido fazer, pensar ou sentir" ela seria normativa.

Da mesma forma que Putnam, Gibbard evita a metafísica inflacionada de Moore e sustenta que "nossa capacidade normativa pode ser explicada sem supor que exista um tipo especial de fato normativo ao qual tipicamente respondemos", a saber, as propriedades não naturais e não metafísicas de Moore. De um ponto de vista da biologia evolutiva, Gibbard afirma, que, em vez de supor uma faculdade especial de apreensão de valores, podemos pensar que "temos essas capacidades porque elas coordenam nossas ações de maneira mutuamente benéficas" (Gibbard 1990, p.107). E continua na mesma passagem: "podemos ilustrar como a biologia pode estabelecer se existem fatos normativos. Se a hipótese se sustenta, nós não precisamos de fatos normativos para explicar a emissão dos juízos normativos que emitimos. Nosso ato de emiti-los deve ser explicado pelas recompensas da coordenação. Supor que existem fatos normativos é gratuito."

Mais adiante ele afirma que:
Aqui os mecanismos psiquicos que produzem fatos normativos não são siste- mas de representação natural, eles são sistemas de coordenação. Sua função biológica não é colocar algo na cabeça em correspondência com seu objeto [subject matter]; é coordenar o que está na cabeça de uma pessoa com o que está na de outra pessoa. Portanto, os juizos não são representações naturais mas outra coisa. Podemos chamá-las de 'conações naturais', pois sua função biológica é coordenar nossas ações, crenças e emoções.

Ou seja, juizos morais para Gibbard não tem a função de representar objetos existentes independentemente da mente daqueles que os empregam, mas antes apenas 
coordenar o comportamento dos seres humanos, uma vez que expressam a aceitação de regras acerca de quando sentir culpa ou ressentimento.

Gibbard também se preocupa com a acusação de que os juízos morais seriam carentes de objetividade, como vimos, uma das críticas à ética que Putnam buscou refutar (1990, p.153). Ele começa afirmando que uma das principais razões de dúvida em relação a qualquer teoria expressivista é que as mesmas "tem um ar de 'subjetivismo' ". Não obstante, diz ele,

No sentido estrito, nenhuma análise expressivista é 'subjetivista'. Para ser subjetivista, a análise teria de dizer que quando uma pessoa chama algo de racional, ela está reportando um estado mental: ela está dizendo que alguém - seja ela, ou seu grupo, ou talvez o agente ou o grupo de agentes — está em um estado mental particular com relação a essa coisa. É fácil confundir a análise expressivista com as análises subjetistas. (Gibbard 1990, p.153)

Para Gibbard, então o expressivismo não afirma que quando alguém profere um enunciado moral ele está apenas afirmando que 'ele aceita um sistema de normas que permite um certo curso de conduta a seguir', mas antes 'que ele expressa sua aceitação de um sistema de normas que permite um certo curso de conduta a seguir'. Nas palavras de Gibbard, "expressar um estado mental não é dizer que se está nele" (1990, p.154).

\section{A Proposta de Gibbard à luz das críticas de Putnam}

Como vimos, Putnam critica algumas abordagens ética contemporâneas por reduzirem os enunciados morais a enunciados subjetivos, acusando-os de serem carentes de sentido ou simples contra-sensos. A questão que precisa ser respondida agora é se o expressivismo de normas de Gibbard sobrevive às objeções de Putnam. Por isso, serão examinados pontualmente alguns aspectos do expressivismo de normas que poderia sugerir que essa abordagem da ética se compromete com o que Putnam quer evitar, a saber:

(a) a vinculação dos juízos morais a expressão de sentimentos e ao não cognitivismo parece distanciar a posição de Gibbard da de Putnam, uma vez que este tentou aproximar juízos científicos e morais, o que pode sugerir que os juízos morais assim como os científicos são portadores de valor de verdade, por isso Putnam seria um cognitivista e não um não cognitivista moral como Gibbard. Além disso, o argumento de Putnam aqui poderia ser apresentado da seguinte maneira, como diz Bernstein (p.251), "a dúvida exige justificação assim como a crença", por isso a negação do caráter cognitivo aos enunciados morais também exige justificação, ou seja, Gibbard

Principia 17(3): 489-503 (2013). 
tem que explicar porque atribui um estatuto epistêmico não cognitivo aos enunciados morais. $\mathrm{O}$ argumento geralmente diz respeito ao desacordo moral reinante, contudo, primeiro, Putnam é contrário "a própria ideia de explicar como o conhecimento ético é possível em termos absolutos" (2002, p.44). Segundo, a aproximação das proposições éticas às matemáticas (ambas podem ser objetivas sem referir-se a objetos fora da mente), as quais nunca se recusou o estatuto de cientifidade, leva à atribuição de verdade e validade (2004, p.54) aos enunciados éticos, uma vez que Putnam dá a entender que ambas são proposições assertóricas.

(b) não obstante, tanto Putnam quanto Gibbard vinculam os juizos morais à objetividade. Putnam faz isso em parte afirmando que, se negássemos como faz o naturalismo extremo "a objetividade a todos os valores éticos deveríamos, para ser consistentes, negar toda a objetividade aos valores metodológicos também - uma posição que ninguém deveria abraçar". (Putnam 2004, p.72). Gibbard, por sua vez, compreende que os juízos morais podem ser objetivos porque podem surgir de discursos racionais a respeito de quando faz sentido sentir culpa, louvor e ressentimento. Ou seja, Gibbard assim como Putnam acredita que é possível alcançar alguma objetividade aos enunciados morais, uma vez que seria possível chegar a algum acordo intersubjetivo a respeito de quando é racional sentir culpa ou ressentimento diante de certas circunstâncias. Não obstante, é importante ressaltar que Gibbard ainda vincula julgamentos morais a sentimentos, razão pela qual recusa o cognitivismo moral.

(c) embora Gibbard vincule aos enunciados morais a situações em que é apropriado sentir culpa e louvor, não parece óbvio que Putnam aceitaria que essa é uma característica distintiva dos enunciados morais. Putnam (2004, p.73), por sua vez, afirma que embora alguns juízos morais envolvam culpa e louvor, outros juízos éticos não tem nada a ver com isso. Ele até mesmo cita o exemplo do terremoto de Lisboa de 1755, um evento que teria sido um grande mal, embora nesse caso não se trata de prescrever culpa a ninguém. Além disso, Putnam entende que há juízos éticos que envolvem prescrever comportamentos (com os termos 'dever', etc), mas também há juizos éticos que não envolvem esse tipo de prescrição, uma vez que tratam da "solução de problemas práticos altamente específicos e situados" (2004, p.73).

(d) quanto à vinculação dos enunciados morais à propriedades naturais ou físicas dos objetos, ambos parecem se opor a qualquer identificação entre os juízos morais e o naturalismo extremo: de certa forma, Putnam e Gibbard igualmente se opõem ao afirmarem que enunciados morais não tratam de meras descrições do que se tem na mente. Gibbard afirma que juízos morais tratam de enunciados relativos a expressão da aceitação de normas a respeito do que é permitido ou proibido, embora Putnam também reconheça que alguns juízos éticos são descrições (2004, p.74). Se bem que faça parte da estratégia geral de Putnam minar a própria distinção forte entre fatos 
e normas, razão pela não apenas é importante ressaltar, contra os positivistas lógicos que fatos não estão isentos de valores, mas também que valores envolvem fatos, envolvem descrições da realidade.

\section{Críticas de Habermas à proposta de Gibbard}

Em Eine genealogische Betrachtung zum kognitiven Gehalt der Moral, Habermas (1999, p.29) tece algumas considerações críticas em relação à proposta oferecida por Gibbard de explicar a moral de um ponto de vista functional à luz da biologia evolutiva. Primeiramente, a abordagem expressivista de normas carece de uma noção de racionalidade para explicar a normatividade das regras morais que pudesse ser reconhecida pelos participantes da perspectiva performativa e não apenas da perspectiva do observador (da biologia evolutiva). A autoridade das normas morais é explicada apenas da perspectiva do observador com base no valor reprodutivo das normas internalizadas com seus respectivos sentimentos. Contudo, conforme Habermas, ainda fica pendente a tarefa de estabelecer uma conexão plausível entre aquilo que é funcional do ponto de vista do observador e aquilo que é racional da perspetiva daqueles que participam do jogo moral de sua própria perspectiva perfomativa. Que este é um problema que esse tipo de teoria moral precisa enfrentar é algo que fica mais evidente quando se discute explicitamente "quais são as normas que devem ser admitidas como válidas" (Habermas 1999, p.30).

Conforme Habermas (1999, p.30), Gibbard reconhece o papel da linguagem como meio de coordenação das ações dos integrantes da espécie homo sapiens sapiens, e que a linguagem entraria em ação principalmente "quando o consenso normativo de fundo desmorona e novas normas precisam ser elaboradas". Entretanto, para Habermas (1999, p.32), não fica claro que considerações podem ser utilizadas como apoio a uma instrução normativa nesse tipo de discurso. Para Habermas (1999, p.31) está claro que não poderiam ser bons motivos, uma vez que bons motivos derivam sua força racionalmente motivante de padrões internalizados, "a respeito dos quais se pressupõe que perderam sua autoridade - caso contrário não teria surgido a necessidade de um entendimento discursivo". A partir disso Habermas (1999, p.31) chega a conclusão de que "Gibbard não poderia compreender o entendimento discursivo" a respeito das normas controversas no padrão de uma busca cooperativa da verdade, como faz a própria ética discursiva, mas antes apenas como um processo de "mútua influenciação retórica". Ou seja, aqueles que participam da interação linguistica moral poderiam na melhor das hipóteses contagiar, mas nunca convencer seus interlocutores, desse modo "o convencimento mútuo é substituído por algo assim como uma harmonização recíproca" (Habermas 1999, p.31). Por conseguinte, não parece adequado falar de fundamentação moral do ponto de vista do expressivismo de normas.

Principia 17(3): 489-503 (2013). 
Conforme Habermas (1999, p.32) Gibbard precisa explicar por que os seres humanos em sua discussão normativa teriam que chegar a exatamente aquelas normas que se mostram as melhores do ponto de vista funcional e de seu 'valor de sobrevivência'. Ou seja, ele teria que explicar de que modo podem ser compatíveis as normas que seriam melhores da perspectiva do observador, baseado na biologia evolutiva darwinista, com aquelas que seriam alcançadas pelos participantes da discussão da sua própria perspectiva, enquanto participantes dos debates normativos orientados ao consenso. Para Habermas, uma maneira de Gibbard contornar esse tipo de problema para sua abordagem expressivista de normas seria mediante a apropriação pelos participantes das descrições biológicas, não obstante, esse tipo de estratégia "destruiria a autoconsciência prática dos sujeitos capazes, ou, no caso da mudança do observador, mudaria essencialmente o seu sentido da perspectiva dos participantes" (Habermas 1999, p.32, nota). Ou seja, Habermas compreende que para alcançar esse tipo compatibilização entre as normas acordadas em uma discussão normativa orientada ao consenso e os valores de uma perspectiva biológica evolutiva, ele cairia em um tipo de dilema: ou teria que deixar de prestar contas a faculdade de deliberação prática, que os seres humanos se atribuem mutuamente de forma intuitiva (à nossa fenomenologia moral), ou teria que abandonar completamente a perspectiva do participante e restringir-se a ponto de vista do observador. Desse modo, ele parece concluir que a explicação biológica da ética expressivista de normas não seria capaz de ofercer uma explicação plausível de nossa fenomenologia moral ordinária e, consequentemente, poder-se-ia sustentar que ela seria uma abordagem metafisicamente menos carregada, contudo, insuficiente da moralidade. O que poderia ser considerado uma evidência senão da falta de relevância da biologia na deliberação moral, ao menos da insuficiênica de uma explicação a respeito de como funciona a reflexão moral.

\section{Considerações finais}

Embora não tenha sido objetivo do presente artigo tratar do debate entre Habermas e Putnam a respeito da distinção entre valores e normas, algo que Putnam diz ao discutir a posição de Habermas ajuda a esclarecer o que ele pensa das tentativas de explicar a ética à luz da biologia. Putnam afirma:

Embora o desejo de 'naturalizar' a ética seja extremamente difundido, o 'preço' da naturalização é extremamente alto.[...] Todas as análises naturalistas têm em comum que elas ou negam que sentenças éticas sejam expressões de julgamentos, de pensamentos que podem ser descritos como verdadeiros ou falsos, justificados ou injustificados, [...] ou [afirmam que são] 'relativos aos desejos individuais e atitudes' ou (se concordam que exista coisas como julgamentos completamente racionais e objetivos) oferecem uma

Principia 17(3): 489-503 (2013). 
análise do propósito (e às vezes do conteúdo) de tais juízos em termos não éticos. (Putnam 2002, p.131; grifos do autor, nossa tradução)

Putnam inclui as abordagens que pretendem explicar a ética à luz da biologia no terceiro grupo da disjunção, ou seja, entre aqueles que procuram oferecer uma análise do propósito da ética em termos não éticos. Essa visão dá a entender que a ética é algo que precisa encontrar uma justificação a partir de fora [from outside] (Putnam 2002, p.131). No caso específico de Gibbard, que procure explicar a ética com base na biologia evolutiva, se trata de explicar qual a função ou o propósito da capacidade de raciocionar moralmente ter surgido no processo evolutivo da espécie humana. Putnam acredita que explicar a ética à luz da biologia é uma estratégia sedutora, contudo altamente desastrosa, uma vez que levaria também ao positivismo lógico: à crença que apenas enunciados que puderem ser reduzidos à enunciados a respeito de fatos, nesse caso a respeito de fatos da biologia evolutiva, seriam portadores de significado. Essa visão, como vimos, é algo contra o que Putnam despende grande parte de seus esforços intelectuais em atacar. O problema com esse tipo de abordagem naturalista, para Putnam (2002, p.131-2), é que concede ao cético moral que a ética não constitui nenhum tipo de conhecimento, na medida em que trata obrigações morais como sentimentos, ou na versão mais sofisticada do expressivismo de normas de Gibbard, como a expressão da aceitação de regras que regulam os sentimentos de culpa e ressentimento. Embora seja preciso reconhecer que o expressivismo de normas de Gibbard seja uma vertente mais sofisticada de tentativa de naturalização da ética, uma vez que procura manter a objetividade dos enunciados morais, mesmo sem objetos externos à mente, aos quais os termos morais se refiram, a proposta de Gibbard ainda estaria concedendo ao cético em relação à moralidade, algo que Putnam não está disposto a ceder, a saber, que enunciados morais são carentes de valor de verdade, ou seja, não podem ser considerados verdadeiros ou falsos. Desse modo, por razões diferentes daquelas apresentadas por Habermas (até porque suas críticas parecem se basear na distinção entre normas e valores, que Putnam recusa-se aceitar), Putnam consideraria uma abordagem ética baseada na biologia evolutiva, como a de Gibbard, também insuficiente como uma explicação do fenômeno moral, porque acredita que qualquer explicação da moralidade precisaria prestar contas ao caráter cognitivo dos enunciados morais ou então explicar adequadamente a assimetria no tratamento entre enunciados científicos e enunciados normativos.

\section{Referências}

Bernstein, R. 2005. The Pragmatic Turn: The Entanglement Fact and Value. In: Y. BenMenahen (ed.) Hilary Putnam. Cambridge: Cambridge University Press, p.251-65.

Dall'Agnol, D. 2005. Valor Intrínseco. Metaética, ética normativa e ética prática em G. E. Moore. Florianópolis: Editora da UFSC.

Principia 17(3): 489-503 (2013). 
Gibbard, A. 2002. Wise Choice, Apt Feelings. A Theory of Normative Judgment. Oxford: Clarendon Press.

Habermas, J. 1999. Eine genealogische Betrachtung zum kognitiven Gehalt der Moral. In: J. Habermas, Die Einbeziehung des Anderen. Studien zur Politischen Theorie, Frankfurt: Suhrkamp Verlag.

Hume, D. 1999. An Enquiry concerning Human Understanding. Oxford: Oxford University Press.

Kahane, H. 1995. Contract Ethics. Evolutionary Biology and the Moral Sentiments. London: Roman \& LittleField Publishers.

Mackie, J. L. 1977. Ethics. Inventing Right and Wrong. London: Peguin Books.

Moore, G. E. 1903. Principia Ethica. Cambridge: Cambridge University Press.

Nagel, T. 1991. Mortal Questions. Cambridge: Canto.

Putnam, H. 2003. The Collapse of the Fact-Value Distinction and Other Essays. Cambridge: Harvard University Press.

—. 2004. Ethics without Ontology. Cambridge: Harvard University Press.

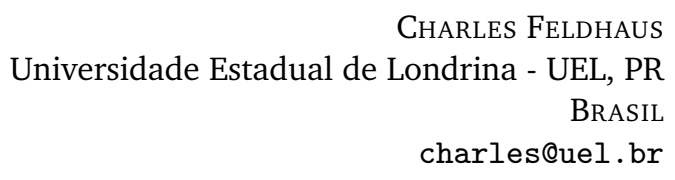

Resumo. Esse artigo reconstrói as principais críticas de Hilary Putnam contra aqueles que tentam desqualificar a filosofia moral baseando-se em considerações ontológicas e epistêmicas. Os que desqualificam a filosofia moral o fazem dentre outras razões, por que os juízos morais careceriam de cientificidade, na medida em que não haveria objetos correspondentes e, consequentemente, não haveria condições de verdade. Por isso, os juízos morais seriam reduzidos a enunciados meramente emotivos. Em seguida, esse artigo reconstrói os traços gerais do expressivismo de normas de Allan Gibbard à luz das críticas de Putnam. Finalmente, reconstrói algumas das principais críticas de Habermas ao expressivismo de normas de Gibbard.

Palavras-chave: Ética; ontologia; biologia evolutiva; pragmatism; expressivismo de normas.

\section{Notas}

${ }^{1}$ Busquei mostrar em "Teria a abordagem expressivista de normas cometido a falácia naturalista?” Ethic@ - Revista Internacional de Filosofia Moral 10(2): 303-21, 2011, que Gibbard não comete a falácia naturalista.

${ }^{2}$ Em sua obra Die Einbeziehung des Anderen, no capítulo Eine genealogische Betrachtung zum kognitiven Gehalt der Moral.

Principia 17(3): 489-503 (2013). 